\title{
Inhibición del crecimiento de Erwinia chrysanthemi a diferentes concentraciones de ácido fólico: posible uso del ácido fólico como agente bacteriostático y fortificante de la papa Solanum tuberosum
}

\author{
Inhibition of Erwinia chrysanthemi growth to different concentrations of folic acid: possible use of folic acid as \\ bacteriostatic agent and fortifying of Solanum tuberosum potato
}

\author{
Andrea Marcelo-Correa ${ }^{1 *}$ orcid.org/0000-0003-4012-4449 \\ Adriana Ordóñez-Vásquez ${ }^{2}$ orcid.org/0000-0003-1510-0189 \\ Alba Alicia Trespalacios ${ }^{3}$ orcid.org/0000-0002-7540-5868 \\ Fernando Suárez-Obando2,4 orcid.org/0000-0001-6336-5347
}

\begin{abstract}
Estudiante de MBA Pontificia Universidad Javeriana.
Instituto de Genética Humana, Facultad de Medicina Pontificia Universidad Javeriana.

Grupo de Enfermedades Infecciosas, Facultad de Ciencias Pontificia Universidad Javeriana.

Servicio de Genética, Hospital Universitario San Ignacio.
\end{abstract} diferentes concentraciones de ácido fólico: posible uso del ácido fólico como agente bacteriostático y fortificante de la papa Solanum tuberosum. Univ. Salud. 2017;19(1):140-148. DOI: http://dx.doi.org/10.22267/rus.171901.77

\begin{abstract}
Resumen
Introducción: Las enterobacterias del genero Erwinia spp producen enfermedades en la papa, un tubérculo de consumo masivo. La regulación de la metilación del DNA puede regular la proliferación de la Erwinia, de tal modo que las concentraciones del ácido fólico, pueden tener un efecto en la capacidad patógena del microorganismo. De otra parte, el ácido fólico previene la aparición de defectos del tubo neural en humanos. Objetivo: Evaluar al ácido fólico como un agente bacteriostático de la Erwinia y que a su vez sea parte de la fortificación de alimentos de consumo masivo como la papa. Materiales y métodos: Se llevó a cabo la caracterización bioquímica de la Erwinia chrysanthemi, se estudió su crecimiento frente a diferentes concentraciones de ácido fólico Resultados: Al aumentar las concentraciones de la vitamina, desde $0,3 \mu \mathrm{g} / \mathrm{L}$ hasta $6,8 \mu \mathrm{g} / \mathrm{L}$ se inhibe el crecimiento bacteriano de la Erwinia chrysanthemi. La vitamina inhibe el crecimiento en cultivo de Erwinia chrysanthemi y actúa como agente bacteriostático, aspecto de gran relevancia dado que teóricamente, si la papa estuviera fortificada con el micronutriente, este actuaría contra el agente infeccioso y al mismo tiempo contribuiría al consumo adecuado de la vitamina en la población general.
\end{abstract}

Palabras clave: Ácido fólico; Erwinia; Solanum tuberosum; crecimiento bacteriano; técnicas de tipificación bacteriana. (Fuente: DeCS, Bireme).

\begin{abstract}
Introduction: The enterobacteria of the Erwinia spp genus produce disease in potatoes, which is a tuber of mass consumption. The regulation of DNA methylation can regulate the proliferation of Erwinia in such a way that the
\end{abstract}


concentrations of folic acid may have an effect on the microorganism pathogenic ability. On the other hand, the folic acid prevents the appearance of neural tube defects in humans. Objective: To evaluate folic acid as a bacteriostatic agent of Erwinia and, at the same time, as part of the fortification of mass consumption food such as the potatoes. Materials and methods: The biochemical characterization of the Erwinia chrysanthemi was carried out and its growth compared to different concentrations of folic acid was studied. Results: When increasing the concentrations of the vitamin from $0.3 \mu \mathrm{g} / \mathrm{L}$ up to $6.8 \mu \mathrm{g} / \mathrm{L}$, the bacterial growth of Erwinia chrysanthemi is inhibited. The vitamin inhibits the growth in cultivation of Erwinia chrysanthemi and acts as a bacteriostatic agent. This aspect is of great importance given that, theoretically, if potatoes were fortified with micro-nutrient, this would act against the infectious agent and, at the same time, contribute to the adequate intake of the vitamin in the general population.

Keywords: Folic acid; Erwinia, Solanum tuberosum; bacterial growth; bacterial typing techniques. (Source: DeCS, Bireme).

\section{Introducción}

Después de los cultivos de granos como el arroz y el trigo, la papa (Solanum tuberosum) es el cultivo alimenticio más importante del planeta1, En Colombia es una de las actividades agrícolas más significativas de la economía y es la principal fuente productiva del piso térmico frío, específicamente de los altiplanos y los páramos ${ }^{2}$. Se estima que en Colombia, para el año 2013, se produjeron alrededor de dos millones doscientos mil toneladas del tubérculo, siendo el cuarto cultivo de mayor producción, después de la caña de azúcar, el banano y la palma ${ }^{3}$. El cultivo y la producción de papa se ven afectados por múltiples factores, dentro de los cuales se destacan, los agentes fitopatógenos que infectan el tubérculo y se multiplican en el mismo, gracias a su alto contenido de almidones y azúcares ${ }^{4}$.

Dentro del grupo de bacterias que generan enfermedades de alto impacto en la papa, se destacan las enterobacterias del género Erwinia $s p$, que producen enfermedades como la podredumbre blanda y la pierna negra ${ }^{5}$. Las Erwinias patógenas se encuentran en las superficies de las raíces y hojas de las plantas e ingresan al organismo a través de lesiones en los tallos, hojas o raíces o también utilizan a los lenticelos como canal de ingreso ${ }^{6}$. Una vez dentro de la planta, la bacteria se establece en los espacios intercelulares y sólo inicia su proceso de infección cuando las condiciones ambientales de oxígeno, disponibilidad de agua $y$ temperatura se lo permiten ${ }^{6}$. El proceso de infección, es mediado por exoenzimas de tipo pectinasas, celulasas y proteasas que atacan la pared celular de la planta y deterioran el tejido ${ }^{6,7}$ Estas bacterias han desarrollado resistencia a diversos agentes bactericidas, debido al uso excesivo de plaguicidas ${ }^{8}$. A pesar de este fenómeno, la evaluación de otras sustancias no tóxicas, que puedan llegar a tener un efecto bactericida o bacteriostático contra este microorganismo, ha sido limitada 9 .

Una alternativa a los plaguicidas es la de estimular en la planta, una respuesta de resistencia a los patógenos luego de exponer al vegetal a un inductor de mecanismos de defensa ${ }^{10}$. Este agente ambiental inductor, puede ser biótico (hongos, virus, bacterias, nematodos) o abiótico (proteínas, ácidos grasos, glicoproteínas, péptidos, glicolípidos, lípidos, oligosacáridos y polisacáridos) ${ }^{11}$. Este planteamiento se implementa bajo el supuesto que el inductor, además de mejorar la capacidad de respuesta de la planta ante el patógeno, no inhibe su crecimiento o desmejora el rendimiento del cultivo ${ }^{12}$.

Se ha planteado para el caso de la Erwinia sp, que la regulación de la metilación del DNA puede regular su virulencia ${ }^{13}$. Este fenómeno esta mediado por diversos grupos de metilasas, como por ejemplo la DNA metil-transfersa de $\gamma$ proteobacterias, que metila la adenina en la posición N6 en las secuencias GATC $^{14}$ en contraste con otras familias de metil trasferasas que metilan la posición C-5 or N-4 de la citosina. Uno de los resultados, de la regulación de la expresión, por metilación de ciertos genes bacterianos, es la regulación del ciclo celular, controlando la proliferación bacteriana ${ }^{13}$. A su 
vez, los eventos de metilación, que ejercen sus efectos regulatorios, tienen íntima relación con el metabolismo del ácido fólico ${ }^{15}$, lo cual se ha inferido a través de estudios en los que el precursor del folato, el ácido para aminobenzoico (PABA) se ha utilizado como agente inductor de resistencia contra fitopatógenos, como por ejemplo, en el caso de inducción de resistencia adquirida del Capsicum annuum (Pimiento) a la bacteria Xanthomonas axonopodis pv. vesicatoria, luego de la exposición a PABA ${ }^{16}$. El proceso de metilación está relacionado con al metabolismo del ácido fólico, debido a que esta vitamina es la fuente del grupo carbono, utilizado para metilar el DNA ${ }^{17,18}$. Es así, como se plantea que diferentes concentraciones del ácido fólico, pueden tener un efecto en la proliferación y capacidad patógena del microorganismo Erwinia $s p$ al metilar genes de regulación de ciclo celular ${ }^{19}$, de tal modo que esta vitamina tendría el potencial de utilizarse como un elemento que modifique los mecanismos bacterianos, que afectan los cultivos de papa, al inducir resistencia a la infección.

El ácido fólico (ácido pteroil-L-glutamico) es una vitamina hidrosoluble del complejo de la vitamina $B$, necesaria para diversos procesos bioquímicos, tales como la formación de proteínas estructurales, síntesis de nucleótidos y regulación epigenética, entre otros ${ }^{20}$. El ácido fólico es de particular interés clínico en seres humanos, por su relación con la anemia megaloblástica y diversos trastornos neurológicos relacionados con su carencia ${ }^{21,22}$, además de su comprobada eficacia en la prevención de (Defectos del Tubo Neural (DTN)) cuando se consume previamente al embarazo ${ }^{23}$.

En Colombia, hay un consumo deficitario de ácido fólico en mujeres en edad fértil ${ }^{24,25}$ y existe una escasa percepción sobre su importancia en la salud materna fetal ${ }^{26}$, a pesar que la fortificación de alimentos de consumo masivo con ácido fólico ha demostrado disminuir la prevalencia de los DNT$^{27}$ y teniendo en cuenta el consumo y producción de la papa, este alimento ha sido uno de los alimentos candidatos para dicha fortificación ${ }^{28}$.
De acuerdo a estas consideraciones, el presente estudio evaluó el crecimiento del fitopatógeno Erwinia sp frente a diferentes concentraciones de ácido fólico y se propone a esta sustancia como un agente abiótico inductor de defensas que, además de tener un potencial en la prevención de enfermedades de la papa, pueda actuar como un fortificante nutricional de Solanum tuberosum que contribuya a la prevención de los DTN.

\section{Materiales y métodos}

Esta es una investigación cuantitativa de carácter descriptivo, que evalúa los efectos del ácido fólico en el crecimiento de la Erwinia sp.

\section{Caracterización bioquímica de la cepa de Erwinia sp}

Las enterobacterias utilizadas para este estudio, se obtuvieron en viales del banco de cepas del laboratorio: The Mycology and Plant Pathology Laboratory (LAMFU) de la Universidad de los Andes ${ }^{29}$, rotuladas únicamente como Erwinia $s p$. A partir de los viales se realizaron siembras masivas por duplicado en agar sangre, agar nutritivo, agar MacConkey y agar TSA. Se llevaron a incubar a $37{ }^{\circ} \mathrm{C}$ durante 48 horas. A partir de las colonias obtenidas se realizó coloración de Gram y una caracterización de la temperatura óptima de crecimiento colocando las bacterias en $10 \mathrm{~mL}$ de caldo nutritivo, el cual se llevó a incubar a temperaturas de $22^{\circ} \mathrm{C}, 30^{\circ} \mathrm{C}$, $35^{\circ} \mathrm{C}$ y $45^{\circ} \mathrm{C}$ durante 24 horas $^{30}$. Se realizó la lectura del crecimiento y se evaluaron pruebas bioquímicas mediante sistemas de identificación multi-pruebas BBL CrystalTM y API 20ETM además de las pruebas de catalasa y oxidasa. Finalmente se evaluó la sensibilidad a la eritromicina mediante siembras por duplicado en agar Mueller Hinton con sensidiscos de $15 \mu \mathrm{g}$ de eritromicina ${ }^{31}$.

\section{Curva de crecimiento de Erwinia sp}

Se recuperó un vial con Erwinia sp, conservado en caldo TSA con glicerol al 20\%, en dos cajas de agar TSA y se incubó durante 24 horas a $35^{\circ} \mathrm{C}$. Posteriormente, se realizó coloración de Gram 
para determinar pureza. Luego, se hizo un raspado de las dos cajas de agar TSA y se suspendió en $10 \mathrm{~mL}$ de caldo Brucella. Se preparó un pre-inóculo de acuerdo al protocolo del British Society for Antimicrobial Chemotherapy (BSAC) en un Erlenmeyer de $500 \mathrm{~mL}$ con $90 \mathrm{~mL}$ de caldo Brucella y se adicionaron $10 \mathrm{~mL}$ del caldo con la cepa de Erwinia sp. Se incubó en un agitador ThermoFisher Scientific modelo MaxQ 4000 Benchtop durante 24 horas a $35^{\circ} \mathrm{C}$ y a $150 \mathrm{rpm}$. A partir del pre-inóculo se realizaron 3 réplicas en Erlenmeyer para realizar los inóculos, en cada réplica se utilizó un Erlenmeyer de $250 \mathrm{~mL}$ al que se le adicionaron $6 \mathrm{~mL}$ del pre-inóculo y 54 $\mathrm{mL}$ de caldo Brucella ${ }^{32}$. Se incubaron $35^{\circ} \mathrm{C}$ a 150 rpm y se realizaron muestreos cada dos horas, durante las primeras 12 horas y a la hora 24 midiendo biomasa por densidad óptica a $530 \mathrm{~nm}$ tomado alícuotas de 1,5 mL.

\section{Crecimiento de Erwinia sp frente a diferentes concentraciones de ácido fólico}

Se utilizó ácido fólico al 97\% (Sigma AldrichTM) y se preparó una solución stock de ácido fólico a una concentración de $20 \mathrm{mg} / \mathrm{L}$ en $\mathrm{NaOH} 1 \mathrm{M}$. A partir de esta solución stock se prepararon diluciones con agua destilada a concentraciones desde $0.6 \mu \mathrm{g} / \mathrm{L}$ hasta $13.6 \mu \mathrm{g} / \mathrm{L}$. La concentración del inóculo adicionada a cada uno de los caldos de prueba corresponde a la escala de 0,5 Mac Farland ${ }^{33}$. Este inóculo se obtuvo después de detener a las 10 horas de cultivo la curva de crecimiento de la Erwinia sp y realizar una dilución 1/20 con caldo nutritivo. El inóculo se preparó así para asegurar que el microorganismo estaba en su punto máximo de fase exponencial y así someterlo a las pruebas de toxicidad según BSAC 33 .

Para el montaje de la prueba se tomó un volumen final de $10 \mathrm{~mL}$, el cual estaba conformado por $4 \mathrm{~mL}$ de ácido fólico de las diferentes concentraciones preparadas, $5 \mathrm{~mL}$ de caldo Brucella y $1 \mathrm{~mL}$ de inóculo. Las pruebas se incubaron a $35^{\circ} \mathrm{C}$ por 24 horas, al final de las cuales se leyó absorbancia a 530nm usando como blanco el caldo Brucella estéril. El diseño experimental tenía una finalidad descriptiva cuyos factores de estudio eran cuasi experimentales porque se estaba evaluando el efecto de una sustancia (ácido fólico) sin aleatorización. La secuencia temporal era transversal y la direccionalidad prospectiva. Para el análisis estadístico se realizaron medidas de tendencia central (desviación estándar, coeficiente de variación y promedios), cada uno de los ensayos se hicieron por triplicado para cada concentración de ácido fólico. El control positivo corresponde a caldo Brucella con la bacteria Erwinia sp a una concentración según la escala de 0,5 Mac Farland y el control negativo corresponde al caldo Brucela con la concentración más alta de ácido fólico utilizada en esta investigación cuyo valor es de $6.8 \mu \mathrm{g} / \mathrm{L}$.

\section{Consideraciones éticas}

El estudio se acoge a los lineamientos de la Resolución 8430 de 1993 del Ministerio de Salud de Colombia en sus artículos 63, 64 y 68 donde se establecen los lineamientos para el trabajo con microorganismos. El estudio se clasifica, de acuerdo riesgo de infección de los microorganismos utilizados como grupo de riesgo I. El estudio fue aprobado por el Comité de curriculum de la carrera de Microbiologia de Facultad de Ciencias Básicas.

\section{Resultados}

\section{Caracterización bioquímica de la Erwinia sp}

A partir de los diferentes aislamientos en los medios TSA, Agar sangre y Agar nutritivo se realizaron los respectivos montajes de pruebas bioquímicas BBL CrystalTM y API 20ETM. Los resultados se describen en la tabla 1. Estas características corresponden a las características bioquímicas reportadas para Erwinia $s p^{5,34-37}$. Sin embargo, no todas las especies y subespecies de este microorganismo son sensibles a la eritromicina, como es el caso de Erwinia carotovora subespecie carotovora y Erwinia carotovora subespecie atroséptica mientras que la Erwinia chrysanthemi si es sensible a la eritromicina $^{31}$. Por lo tanto, al reconocer dicha sensibilidad fue posible identificar al 
microorganismo de los cultivos, como Erwinia chrysanthemi.

Tabla 1. Caracterización de la bacteria Erwinia chrysanthemi. Pruebas bioquímicas para cepa de Erwinia sp en BBL CrystalTM y API 20ETM

\begin{tabular}{|c|c|c|}
\hline $\begin{array}{c}\text { Prueba } \\
\text { Bioquímica }\end{array}$ & Reacción/ Enzimas & $\begin{array}{c}\text { Resultado } \\
\text { de la cepa } \\
\text { Erwinia } \\
\text { sp } \\
\end{array}$ \\
\hline ONPG & Beta-galactosidasa & Positivo \\
\hline CIT & Utilización del citrato & Positivo \\
\hline IND & Producción de indol & Positivo \\
\hline GLU & $\begin{array}{l}\text { Fermentación/ oxidación de la } \\
\text { glucosa }\end{array}$ & Positivo \\
\hline MAN & $\begin{array}{l}\text { Fermentación/ oxidación del } \\
\text { manitol }\end{array}$ & Positivo \\
\hline RHA & $\begin{array}{l}\text { Fermentación/ oxidación de la } \\
\text { ramnosa }\end{array}$ & Positivo \\
\hline SAC & $\begin{array}{l}\text { Fermentación/ oxidación de la } \\
\text { sacarosa }\end{array}$ & Positivo \\
\hline MEL & $\begin{array}{l}\text { Fermentación/ oxidación de la } \\
\text { melobiosa }\end{array}$ & Positivo \\
\hline AMY & $\begin{array}{l}\text { Fermentación/ oxidación de la } \\
\text { amigdalina }\end{array}$ & Positivo \\
\hline ARA & $\begin{array}{l}\text { Fermentación / oxidación de } \\
\text { la arabinosa }\end{array}$ & Positivo \\
\hline NO2 & Reducción de nitratos & Positivo \\
\hline MOB & Movilidad & Positivo \\
\hline $\mathrm{McC}$ & $\begin{array}{l}\text { Crecimiento en agar } \\
\text { MacConkey }\end{array}$ & Positivo \\
\hline $\begin{array}{l}\text { Sensibilidad } \\
\text { a } 15 \mu \mathrm{g} \\
\text { eritromicina }\end{array}$ & $\begin{array}{l}\text { Formación de halos de } 8 \mathrm{~mm} \\
\text { de diámetro a partir de la } \\
\text { siembra masiva de Erwinia sp } \\
\text { en el agar Mueller Hinton. }\end{array}$ & Sensible \\
\hline
\end{tabular}

En la Figura 1 se aprecia la curva de crecimiento de Erwinia chrysanthemi en caldo Brucella en un periodo de incubación de 24 horas con agitación constante a $150 \mathrm{rpm}$ a $35^{\circ} \mathrm{C}$ a partir de mediciones tomadas cada 2 horas hasta la hora 12 y posteriormente la hora 24 .

La Figura 2 presenta la curva de crecimiento de $E$. chrysanthemi en diferentes condiciones de ácido fólico; en cada una de las quince mediciones a las 24 horas de exposición, se apreció una inhibición del crecimiento bacteriano que se incrementaba con la exposición a concentraciones mayores de ácido fólico (Desde $0.3 \mu \mathrm{g} / \mathrm{L}$ a $6.8 \mu \mathrm{g} / \mathrm{L}$ ). El cultivo de control
$(0.0 \mu \mathrm{g} / \mathrm{L})$ se mantuvo constante en cada una de las mediciones.

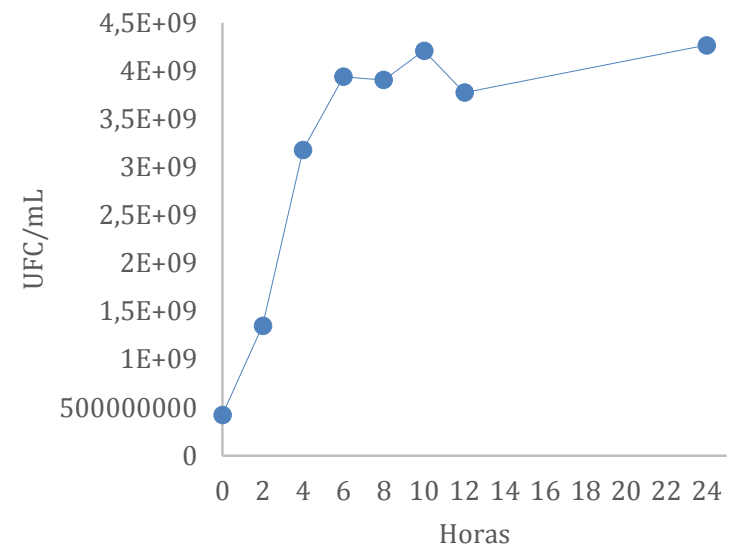

Figura 1. Curva de crecimiento de Erwinia chrysanthemi en caldo Brucella

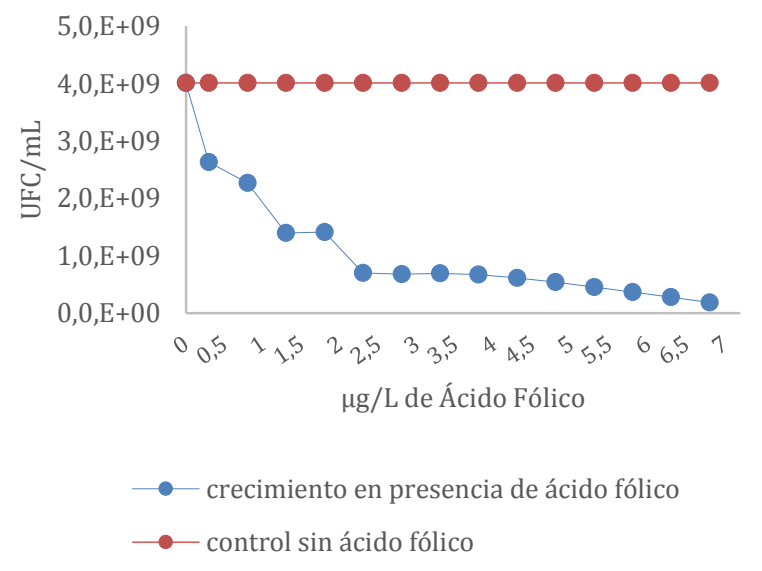

Figura 2. Curva de crecimiento de Erwinia cryzanthemi en diferentes condiciones de ácido fólico

\section{Discusión}

El presente estudio permitió caracterizar e identificar a la Erwinia chrysanthemi, a través de pruebas bioquímicas, establecer su cinética de crecimiento en cultivo y verificar la inhibición de su proliferación con concentraciones incrementales de ácido fólico. Su crecimiento exponencial empieza a las 2 horas de iniciado el cultivo, por lo tanto, su fase de adaptación es corta. Esto se debe a que Erwinia sp se adapta fácilmente a las condiciones de cultivo cuando el medio es altamente nutritivo ${ }^{38-40}$. Por lo tanto, a 
la bacteria le toma muy poco tiempo multiplicar el número de células en un medio como el caldo Brucella que se compone de digestivos pancreáticos de caseína y de tejido animal los que actúan como una fuente importante de carbono y nitrógeno, además de vitaminas que favorecen el crecimiento bacteriano. Adicionalmente, se observa una fase estacionaria larga. Esto se debe a que la fase de muerte de la Erwinia sp inicia a las 48 horas de cultivo ${ }^{38,41}$.

En relación al crecimiento de la E. chrysanthemi frente a diferentes concentraciones de ácido fólico, se puede observar que a medida que se aumenta las concentraciones de la vitamina, desde 0,3 $\mu \mathrm{g} / \mathrm{L}$ hasta $6,8 \mu \mathrm{g} / \mathrm{L}$ se inhibe el crecimiento bacteriano. Una posible explicación a este comportamiento es que la molécula en su forma de cadena larga ingresa directamente al metabolismo del carbono, lo que implica un alto gasto energético para su transporte, de tal modo que, al estar expuesta a concentraciones en exceso, el micronutriente se convierte en un limitante del crecimiento ${ }^{39,42}$. De otra parte, una explicación alterna es que el exceso de ácido fólico en el medio de cultivo podría conducir a una hipermetilación del ADN. Proceso que ocasiona la inducción de heterocromatina que desencadena un silenciamiento de genes relacionados con el crecimiento celular ${ }^{43-45}$. Este proceso de silenciamiento también se ha verificado en células cancerosas de colon, en las cuales el incremento de las concentraciones séricas de ácido fólico reversa la hipometilación, inhibiendo su proliferación ${ }^{46,47}$. Sin embargo, no es un efecto absoluto en todo tipo de células eucariotas, dado que el ácido fólico también ha sido considerado como un factor de riesgo para el crecimiento de ciertos carcinomas ${ }^{48}$.

De otra parte, se debe tener en cuenta al menos dos aspectos importantes en relación a la biomasa de E. chrysanthemi, en el montaje de la prueba de citotoxicidad en los controles, estos son la agitación y el volumen del contenedor donde se realiza la fermentación ${ }^{49}$. Durante la prueba, el experimento se realizó en tubo, no en Erlenmeyer y no se utilizó agitación de acuerdo a lo establecido por el BSAC para pruebas de citotoxicidad en medios de cultivo líquidos. La agitación permite la difusión del oxígeno a lo largo del medio de cultivo y en consecuencia un aumento de la biomasa ${ }^{50}$. Sin embargo, como en el presente experimento no se involucraron estas variables y los datos presentados no están en función del tiempo sino en función de la concentración del ácido fólico, esto explica por qué los controles no aumentaron su biomasa, al menos no en un rango significativo en comparación con las otras pruebas.

Estos hallazgos indican que el ácido fólico actúa principalmente como agente bacteriostático de $E$. chrysanthemi, impidiendo su división e inhibiendo el crecimiento bacteriano. Como se mencionó, este efecto puede estar mediado por hipermetilación, tal como como sucede en la $E$. coli, bacteria en la cual, sitios específicos del DNA (secuencias GATC) localizados en los sitios de origen de la replicación (oriC) ${ }^{51}$, están usualmente hemi-metilados. Sin embargo, un incremento en la metilación ocultaría los oriC inhibiendo consecuentemente la replicación y la división celular ${ }^{52}$. Este aspecto es de gran relevancia dado que teóricamente, si la papa estuviera fortificada con el micronutriente, este actuaría contra el agente infeccioso, inhibiendo su proliferación y al mismo tiempo contribuiría al consumo adecuado de la vitamina en la población general.

De acuerdo a los diferentes estadios de la papa en el cultivo, es posible realizar la fortificación con ácido fólico desde la fase del crecimiento del follaje hasta la tuberización. Esto se debe a que en la etapa del crecimiento del follaje, el tubérculo toma nutrientes provenientes del suelo porque ya ha gastado todas sus reservas ${ }^{53}$. De esta manera, al incluir el ácido fólico desde ese momento del crecimiento, se aseguraría su presencia en el tubérculo hasta el estadio de maduración y posterior cosecha. Adicionalmente, desde la tuberización hasta la senescencia, sucede la acumulación de vitaminas, carbohidratos y otros nutrientes dentro del tubérculo y cerca de las raíces ${ }^{53}$, por lo tanto, en un eventual proceso de fortificación, si la presencia del ácido fólico fuera constante en cualquiera de las dos zonas de la planta (fruto y raíces), se estaría acumulado, al igual que los 
demás nutrientes absorbidos, además el ácido fólico no es utilizado por la planta como fuente importante a nivel nutricional, lo que garantizaría en cierta forma una concentración relativamente constante. De otra parte, se podría aprovechar el riego por goteo para hacer llegar el micronutriente a la planta, dado que es un método fácil y económico que aseguraría el contacto directo de la vitamina con las raíces y yemas en formación de la planta.

Aunque se concluyó que la vitamina inhibe el crecimiento en cultivo de E. chrysanthemi, se debe ser cauteloso frente a estos resultados, dado que el estudio tiene varias limitaciones. En primer lugar se clasificó a la bacteria mediante prueba bioquímicas y sería necesario realizar pruebas moleculares confirmativas (Amplificación de la porción $16 \mathrm{~S}$ del ribosoma o de oligonucleótidos de los genes recA y gpd) para alcanzar a una identificación plena ${ }^{37}$ y luego establecer si la inhibición con ácido fólico también afecta a otras subespecies de Erwinia $s p$ que a su vez también sean fitopatógenas para la papa. Además, si se quiere aprovechar las características del ácido fólico como bacteriostático y micronutriente necesario para la prevención de defectos del tubo neural, se deberán establecer las concentraciones adecuadas de suministro del micronutriente, para que el tubérculo en crecimiento acumule lo suficiente para inhibir el crecimiento bacteriano y mantenerse en la concentración suficiente para que la papa sea un alimento fortificado, desde su etapa de crecimiento.

El fortalecimiento de otros tipos de cultivo, como el tomate, con precursores del ácido fólico como el para-amino benzoato, ha sido demostrado, sin embargo, existen limitaciones en la fortificación con ácido fólico en vegetales como Arabidopsis thaliana y tubérculos como la papa ${ }^{54,55}$. Estas limitaciones se deben a que los pasos del metabolismo de síntesis del ácido fólico, que han sido introducidos de manera exitosa en el tomate o el arroz, no son suficientes para alcanzar concentraciones significativas y uniformes en el almidón de la papa ${ }^{55}$. La regulación de esta síntesis depende en parte de la diversidad genética de las especies de Solanum, lo que puede ser una alternativa a la producción del ácido fólico en la planta, dado que especies como la Solanum vernei y Solanum boliviense tiene el potencial de producir más del doble de ácido fólico que el Solanum tuberosum ${ }^{56}$.

El trabajo futuro se debe encaminar a la fortificación del tubérculo con el ácido fólico, de tal modo que su aprovechamiento como alimento básico se amplié hacia la prevención de enfermedades humanas como los DTN y a su vez se fortalezca la planta frente a las agresiones de bacterias como la Erwinia sp. Este trabajo es un primer paso en verificar la capacidad del ácido fólico de inhibir a este patógeno.

Conflicto de intereses: Ninguno declarado.

\section{Referencias}

1. Potato Genome Sequencing $\mathrm{C}, \mathrm{Xu} \mathrm{X}$, Pan $\mathrm{S}$, Cheng $\mathrm{S}$, Zhang B, Mu D, et al. Genome sequence and analysis of the tuber crop potato. Nature. 2011 Jul 14;475(7355):189-95.

2. Superintendencia, Industria y comercio. Cadena productiva de la papa: diagnóstico de libre competencia. 2013 [consultado 2015 Octubre 24]; Disponible en: http://www.sic.gov.co/drupal/sites/default/files/files /PAPA.pdf.

3. Food and agriculture organization of the United Nations. Statistic Division. FAOSTAT. 2015 [consultado 2015 Octubre 24]; Disponible en: http://faostat3.fao.org/browse/Q/QC/E.

4. Franco Y, Stefanova M, Coronado M. Patogenicidad y Virulencia de asilamiento de Erwinia sp. en semillas de papa importada. Fitosanidad. 2004;8(4):45-7.

5. Duarte V, de Boer SH, Ward LJ, de Oliveira AM. Characterization of atypical Erwinia carotovora strains causing blackleg of potato in Brazil. J Appl Microbiol. 2004;96(3):535-45.

6. Rocha-Gracia R, Lozano-Zarain P, Martínez-Laguna Y. Movilidad Bacteriana como un mecanismo de patogenicidad. In: Rocha-Gracia R, Lozano-Zarain P, Martínez-Laguna $\mathrm{Y}$, editors. Mecanismos de patogenicidad e interacción parásito-hospedero II. Puebla: Bénemerita Universidad Autónoma de Puebla; 2006.

7. Huang HE, Ger MJ, Chen CY, Pandey AK, Yip MK, Chou $\mathrm{HW}$, et al. Disease resistance to bacterial pathogens affected by the amount of ferredoxin-I protein in plants. Mol Plant Pathol. 2007; Jan;8(1):129-37.

8. Nissen J, Carrión J, Ciampi L, Costa M, Fuentes R, Schöbitz R. Biocontrol of Erwinia $s p$ on calla (Zantedeschia sp). Agro Sur. 2008;36(2):59-70. 
9. Acimovic SG, Zeng Q, McGhee GC, Sundin GW, Wise JC. Control of fire blight (Erwinia amylovora) on apple trees with trunk-injected plant resistance inducers and antibiotics and assessment of induction of pathogenesis-related protein genes. Front Plant Sci. 2015;6:16.

10. Borges AA, Sandalio LM. Induced resistance for plant defense. Frontiers in plant science. 2015;6:109.

11. Ramegowda V, Senthil-Kumar M. The interactive effects of simultaneous biotic and abiotic stresses on plants: Mechanistic understanding from drought and pathogen combination. Journal of Plant Physiology. 2015;176:4754.

12. Aranega-Bou P, de la OLM, Finiti I, Garcia-Agustin P, Gonzalez-Bosch C. Priming of plant resistance by natural compounds. Hexanoic acid as a model. Frontiers in plant science. 2014;5:488.

13. Low DA, Weyand NJ, Mahan MJ. Roles of DNA adenine methylation in regulating bacterial gene expression and virulence. Infect Immun. 2001; 69(12):7197-204

14. Heusipp G, Falker S, Schmidt MA. DNA adenine methylation and bacterial pathogenesis. Int J Med Microbiol. 2007; Feb;297(1):1-7.

15. Crider KS, Yang TP, Berry RJ, Bailey LB. Folate and DNA methylation: a review of molecular mechanisms and the evidence for folate's role. Adv Nutr. 2012 Jan;3(1):21-38.

16. Song GC, Choi HK, Ryu CM. The folate precursor paraaminobenzoic acid elicits induced resistance against Cucumber mosaic virus and Xanthomonas axonopodis. Ann Bot. 2013;111(5):925-34.

17. Crider KS, Yang TP, Berry RJ, Bailey LB. Folate and DNA methylation: a review of molecular mechanisms and the evidence for folate's role. Adv Nutr. 2012;3(1):2138.

18. Balaghi M, Wagner C. DNA methylation in folate deficiency: use of CpG methylase. Biochem Biophys Res Commun. 1993;193(3):1184-90.

19. Collier J, McAdams HH, Shapiro L. A DNA methylation ratchet governs progression through a bacterial cell cycle. Proc Natl Acad Sci U S A. 2007;104(43):17111-6.

20. Anderson OS, Sant KE, Dolinoy DC. Nutrition and epigenetics: an interplay of dietary methyl donors, onecarbon metabolism and DNA methylation. J Nutr Biochem. 2012 Aug;23(8):853-9.

21. Chandra J. Megaloblastic anemia: back in focus. Indian J Pediatr. 2010;77(7):795-9.

22. Koike H, Takahashi M, Ohyama $K$, Hashimoto $R$, Kawagashira Y, Iijima M, et al. Clinicopathologic features of folate-deficiency neuropathy. Neurology. 2015;84(10):1026-33.

23. Wilson RD, Genetics C, Wilson RD, Audibert F, Brock JA, Carroll J, et al. Pre-conception Folic Acid and Multivitamin Supplementation for the Primary and Secondary Prevention of Neural Tube Defects and Other Folic Acid-Sensitive Congenital Anomalies. J Obstet Gynaecol Can. 2015 Jun;37(6):534-52.

24. Profamilia. Encuesta Nacional de Demografía y Salud; 2010.

25. Prada G, Soto A, Herrán O. Consumo de leguminosas en el departamento de Santander. Colombia. 2000-2003.
Archivos latinoamericanos de Nutrición. 2005;55(1):64-70.

26. Ordoñez A, Suárez-Obando F. Exploración sobre los conocimientos del ácido fólico y sus beneficios en la salud reproductiva en una población universitaria colombiana. Revista Colombiana de Obstetricia y Ginecología. 2006;57(4):271-8.

27. Castilla EE, Orioli IM, Lopez-Camelo JS, Dutra Mda G, Nazer-Herrera J, Latin American Collaborative Study of Congenital M. Preliminary data on changes in neural tube defect prevalence rates after folic acid fortification in South America. Am J Med Genet A. 2003;123A(2):123-8.

28. Goyer A, Sweek K. Genetic diversity of thiamin and folate in primitive cultivated and wild potato (Solanum) species. J Agric Food Chem. 2011;59(24):13072-80.

29. LAMFU. The Mycology and Plant Pathology Laboratory. Universidad de Los Andes. 2015 [consultado 201512 de diciembre]; Disponible en: http://lamfu.uniandes.edu.co/

30. Moh A, Massart S, Lahlali R, Jijakli M. Predictive modelling of the combined effect of temperature and water activity on the in vitro growth of Erwinia spp. Biotechnology Agronomy Society Enviromental. 2011;15(3):379-86.

31. Kunstmann J, Ciampi L, Böhm L, Barrera S, Collado L. Determinación de especies de Erwinia (grupo carotovora) como agentes causales de pudrición blanda. Agricultura Técnica. 2006;66(3):247-55.

32. Kawaguti HY, Harumi Sato H. Effect of concentration and substrate flow rate on isomaltulose production from sucrose by Erwinia $s p$. cells immobilized in calcium-alginate using packed bed reactor. Appl Biochem Biotechnol. 2010;162(1):89-102.

33. BSAC. British Society for Antimicrobial Chemotherapy. Methods for Antimicrobial Susceptibility Testing. Londres: BSAC; 2013.

34. Rhim S, VoÈlksch B, Gardan L, Paulin J, Langlotz C, Kim W. Erwinia pyrifoliae, an Erwinia species different from Erwinia amylovora, causes a necrotic disease of Asian. Plant Pathology. 1999;48:514-20.

35. Kado C. Erwinia and Related Genera. In: Dworkin M, Falkow S, Rosenberg E, Schleifer K-H, Stackebrandt E, editors. The Prokaryotes: Springer New York; 2006. p. 443-50.

36. Yishay M, Burdman S, Valverde A, Luzzatto T, Ophir R, Yedidia I. Differential pathogenicity and genetic diversity among Pectobacterium carotovorum ssp. carotovorum isolates from monocot and dicot hosts support early genomic divergence within this taxon. Environ Microbiol. 2008;10(10):2746-59.

37. Toth IK, Avrova AO, Hyman LJ. Rapid identification and differentiation of the soft rot erwinias by $16 \mathrm{~S}-23 \mathrm{~S}$ intergenic transcribed spacer-PCR and restriction fragment length polymorphism analyses. Appl Environ Microbiol. 2001;67(9):4070-6.

38. $\mathrm{Li} \mathrm{J}$, Jin $\mathrm{Z}, \mathrm{Yu} \mathrm{B}$. Isolation and characterization of aniline degradation slightly halophilic bacterium, Erwinia sp. Strain HSA 6. Microbiol Res. 2010;165(5):418-26. 
39. Shorten PR, Membre JM, Pleasants AB, Kubaczka M, Soboleva TK. Partitioning of the variance in the growth parameters of Erwinia carotovora on vegetable products. Int J Food Microbiol. 2004;93(2):195-208.

40. Yahiaoui-Zaidi R, Jouan B, Andrivon D. Biochemical and molecular diversity among Erwinia isolates from potato in Algeria. Plant Pathology. 2003;52(1):28-40.

41. Leporq B, Deremaux L, Demeurisse V, Kubaczka M, Dubois J, Membré J. Validation of predictive models in dynamic conditions: Microbial proliferation of Erwinia carotovora spp carotovora at low changing temperatures. Acta Horticulturae. 2001;566:137-42.

42. Shane B. Folate status assessment history: implications for measurement of biomarkers in NHANES. Am J Clin Nutr. 2011;94(1):337S-42S.

43. Sandoval J, Esteller M. Cancer epigenomics: beyond genomics. Curr Opin Genet Dev. 2012;22(1):50-5.

44. Swayne BG, Kawata A, Behan NA, Williams A, Wade MG, Macfarlane AJ, et al. Investigating the effects of dietary folic acid on sperm count, DNA damage and mutation in Balb/c mice. Mutat Res. 2012;737(1-2):1-7.

45. Bhakkad A. Inactivation of $\mathrm{E}$. coli in the presence of folic acid and pterin-6-carboxylic acid as photosensitizers. Ann Arbor: Lamar University Beaumont; 2009.

46. Pufulete M, Al-Ghnaniem R, Khushal A, Appleby $\mathrm{P}$, Harris N, Gout $S$, et al. Effect of folic acid supplementation on genomic DNA methylation in patients with colorectal adenoma. Gut. 2005;54(5):64853.

47. Mathers JC. Reversal of DNA hypomethylation by folic acid supplements: possible role in colorectal cancer prevention. Gut. 2005;54(5):579-81.

48. Siu MK, Kong DS, Chan HY, Wong ES, Ip PP, Jiang L, et al. Paradoxical impact of two folate receptors, FRalpha and RFC, in ovarian cancer: effect on cell proliferation, invasion and clinical outcome. PLoS One. 2012;7(11):e47201.

49. Schmidt FR. Optimization and scale up of industrial fermentation processes. Appl Microbiol Biotechnol. 2005;68(4):425-35.

50. Deantonio C, Sedini V, Cesaro P, Quasso F, Cotella D, Persichetti F, et al. An Air-Well sparging minifermenter system for high-throughput protein production. Microb Cell Fact. 2014;13:132.

51. Bogan JA, Helmstetter CE. DNA sequestration and transcription in the oriC region of Escherichia coli. Mol Microbiol. 1997;26(5):889-96.

52. Casadesus J, Low D. Epigenetic gene regulation in the bacterial world. Microbiol Mol Biol Rev. 2006;70(3):830-56.

53. Dathe A, Timlin D, Fisher J, Reddy V. Modeling potato root growth and water uptake under water stress conditions. Agricultural and Forest Meteorology. 2014;194:37-49.

54. Blancquaert D, Storozhenko S, Van Daele J, Stove C, Visser RG, Lambert W, et al. Enhancing pterin and paraaminobenzoate content is not sufficient to successfully biofortify potato tubers and Arabidopsis thaliana plants with folate. J Exp Bot. [Research Support, Non-U.S. Gov't]. 2013;64(12):3899-909.
55. Goyer A, Sweek K. Genetic diversity of thiamin and folate in primitive cultivated and wild potato (Solanum) species. Journal of agricultural and food chemistry. [Research Support, Non-U.S. Gov't]. 2011;59(24):13072-80.

56. Robinson BR, Sathuvalli V, Bamberg J, Goyer A. Exploring Folate Diversity in Wild and Primitive Potatoes for Modern Crop Improvement. Genes (Basel). 2015;6(4):1300-14. 